\title{
A Digital Approach to Distance E-Learning Foreign Languages Using a Variety of Learning Resources and Learning Competencies
}

\author{
Anna Kononenko* and Larisa Nedospasova \\ Rostov State Transport University, Rostov-on-Don, Russia
}

\begin{abstract}
The research describes the process of a digital approach in teaching a foreign language using various programs, teaching materials and teaching competencies. Recently, at the development of the distance technologies, the aim is to organize the educational process so that it is given the new educational forms, in terms of quality, a result that is at least the same as traditional ones. In addition, there are many questions related to methods of measuring online learning effectiveness, as it provides an opportunity for continuous learning and improvement of the professional activities. Modern changes in modern social life and culture require a restructuring of the training specialists'system, the development of new technologies in education that implement the training of a person with the necessary social and professional competencies. With the development of new information technologies, the range of up-to-date information platforms is expanding; the conditions are created for the formation of a single global information and educational space on their basis. In this regard, the education system is changing and developing. The application of the most suitable MS Teams platform for implementing the educational process and mastering the necessary competencies is considered. The stages and areas for the implementation of the training material are listed in detail. The authors focus on the relevance of achieving the maximum use of various interactive forms of education using innovative technologies and achieving competencies. The paper examines the use of such technologies, discusses the advantages and disadvantages of using such technologies. Methods and approaches in distance or online learning for the assimilation of educational material and mastering the necessary competencies are determined. The authors suggest a possible application of distance learning as an additional educational resource.
\end{abstract}

\section{Introduction}

The main purpose of mastering the digital approach in teaching a foreign language is the formation of students in a foreign language communicative competence, namely: linguistic, sociolinguistic, sociocultural, discursive and strategic. The average level of proficiency in a foreign language is the

\footnotetext{
*Corresponding author: kononenkocap1@mail.ru
} 
minimum necessary for solving social and communicative problems in various areas of the social, cultural and everyday spheres of activity, as well as at the initial stage of scientific activity and for further self-education. The educational establishments have gained experience in conducting training in a distance format, which revealed the various potential of using educational materials with the use of programs permitted for use in our country. Nowadays, the distance learning is no longer surprising, a number of educational institutions, from professional to secondary professional in Russia and abroad, to one degree or another use distance technologies in the pedagogical process. Most students today consider and choose this form of education as an opportunity to obtain higher education or obtain a second education as the advanced training. Not long ago, the number of students in the world receiving education through distance technologies was slightly higher than the number of full-time students of the whole faculty. Modern trends have to be accepted, and many educational establishments understand this and are developing in this direction. In authors' opinion, it is wright to mention "distance learning" and don't use the "distance education", as it is just a different way of forming a student's knowledge and skills, while the education content remains unchanged. In the works of many modern authors, the problems of the distance learning development in Russia are considered [3, 6-10], but before starting to study the problems, the authors investigated the issue of the feasibility and effectiveness of this form of education using various teaching materials and training competencies.

\section{Materials and Methods}

Gradually, every educational institution quickly and efficiently resolved the issue of using and developing the distance learning. There were different points of view regarding distance learning, especially the capabilities of students were accepted, and also nobody should forget about the academic performance and the need for professional skills of teachers to provide really high-quality teaching, and it was necessary to improve the pedagogical culture of the teacher himself $[1,2]$. The overall experience of distance learning on the part of students included a scope of factors: the convenience, characteristics and willingness of the learners and various conditions that can contribute to improving the quality of learning, but are not paramount. However, at first there were doubts about the form of conducting classes and the interaction between students and teachers. In parallel with the control of conducting classes, students had to master:

- basic grammar rules (at the level of morphology and syntax);

- basic norms of phonetics and vocabulary use;

- requirements for speech and language design of oral and written statements, using the specifics of a foreign language culture;

- the main ways of working on linguistic and speech material;

- the main resources which can effectively fill the existing gaps in language education (types of dictionaries, reference books, computer programs, information sites, text editors).

It was necessary to form and develop the necessary skills and competencies:

1) in the field of listening: to perceive by hearing and understand the main content of simple authentic socio-political, journalistic (media) and pragmatic texts related to various types of speech (message, story, dialogue), as well as highlight relevant / requested information in them;

2) in the field of reading: understand the main content of simple authentic socio-political, journalistic and pragmatic texts (information booklets, brochures / brochures), popular science texts, blogs / websites; highlight relevant / requested information from pragmatic reference and advertising texts;

3) in the field of speaking: start, lead / maintain and end the dialogue-questioning about what he/she saw, read, dialogue-exchange of opinions and dialogue-interview / job interview, observing the norms of speech etiquette, if necessary using strategies to overcome difficulties in the communication process (re-asking, paraphrasing, etc.); to question the interlocutor, ask questions and answer them, express their opinion, request, respond to the interlocutor's proposal (acceptance of the proposal or refusal); make messages and build a monologue-description, monologue-narration and monologuereasoning; participate in the analysis or discussion of the problem;

4) in the field of writing: fill out forms and forms of a pragmatic nature; keep a record of the main thoughts and facts (from audio and reading texts); maintain contacts via e-mail (write personal 
emails) and forums (analyze and discuss student written work); write an essay on a given topic, describe a graphic image.

During a week, the university's management was able to implement a distance learning system, which remained convenient and practical for the entire period of the pandemic. It took about a month for teachers and students to get used to such a system and fully adjust it properly. When studying English, minimum requirements for the knowledge and skills of students were established and the content and types of practical classes were determined. The learning process was designed using modern requirements for the formation of the foreign language communicative competence in students of non-linguistic specialties. As a result of mastering the educational material, the student has mastered the following competencies: linguistic, sociolinguistic, sociocultural, discursive and strategic. Also, students mastered the culture of thinking, the ability to generalize analysis, perception of information, goal setting and the choice of ways to achieve it; showed the ability to selfdevelopment, improve their qualifications and skills.

\section{Results}

To obtain the necessary skills and competencies using educational materials, the process was organized as follows: instead of the usual room numbers, links to the webinar in the MS Teams application were added to the schedule for each lesson, the teacher and students of a certain group followed this link and got into the conference with the possibilities of audio-video interaction, where the education process took place. Microsoft Teams has become the most suitable platform for delivering learning materials and developing the required competencies. Both the teacher and the students could talk, see each other and exchange the necessary text, pictures and files in the chat application. Initially, the teachers were obliged to record the lessons being conducted for the control purpose; later such task lost its mandatory character and was carried out rather for the students' convenience. Anyone who entered the meeting could view it again after completion, which was a clear benefit to the students. In addition to MS Teams, the teaching staff continued to use e-mail to distribute necessary materials and information such as submitting home assignment. In order to control the mastering educational material, the students also sent all the completed assignments to the teachers by mail or in the interaction chat, which was created in the electronic information educational environment of the university. As a result of distance learning, the following tasks have emerged for mastering the curriculum and students had to:

- in listening: to perceive by hearing and understand the main content of authentic, journalistic (media) and pragmatic texts related to various types of speech (message, story, interview), as well as highlight relevant / requested information in them; understand spoken language within the literary norm in everyday, social and social;

- in reading: to understand the main content of authentic texts of a journalistic and pragmatic nature, blogs / websites; view large text while highlighting important details; highlight relevant / requested information in them; read almost independently, changing the type of reading and speed depending on the type of text and task; have a basic stock of the necessary vocabulary;

- in speaking: to lead / maintain and end a dialogue-inquiry about what he/she saw, read, a dialogue-exchange of opinions and a dialogue-interview / interview, observing the norms of speech etiquette, if necessary using strategies for restoring a failure in the communication process (re-asking, paraphrasing, etc.); question the interlocutor, ask questions and answer them;

- in writing: to complete written design assignments.

While learning, the students obtained and developed their own skills: expressing one's thoughts and opinions in interpersonal and business communication in a foreign language; extracting the necessary information from the original text in a foreign language on the problems of familiar topics.

The distance learning program was based on a competency-based approach, and such approach led to the following provisions:

- the formation of competencies relevant for communication in real communication conditions;

- the definition of a set of competencies that ensure successful intercultural professional communication;

- the focus on the effective component of the course;

- the correlation of communication skills with generally recognized levels of the English proficiency; 
- the correspondence of the teaching content to the modern educational paradigm.

The implementation of the competence-based approach was ensured through the following principles:

- personal orientation of the process of teaching and learning English;

- focus on the formation of communicative skills relevant for understanding foreign cultural discourse (when listening / reading) and (in the course of oral and written communication);

- the authenticity of the teaching materials used (audible, visual, graphic);

- the reliance on the independence and responsibility of the student;

- the integrativeness of mastering speech skills and speech means;

- the use of various models and forms of interactivity in the course of the course.

\section{Conclusion}

The form of distance learning presented its advantages and disadvantages for students and teachers. The advantages include time consuming that was previously spent on moving, the ability to review the recording of the lesson, learning and teaching in a comfortable educational environment. Among some disadvantages, one should identify the lack of live communication, the difficulty of monitoring attendance and student interest: a student could be at the webinar, but goes about his business; the need for a teacher to develop a suitable strategy for teaching and monitoring, a low level of assimilation of information by students due to low concentration [1]. The exams were conducted with cameras turned on in accordance with the regulations established before the transition to distance education. However, both the university leadership and the teachers understood that it was impossible to control the student's use of auxiliary sources of information, so the content of the exams underwent minor changes [4]. Consequently, the distance learning with its advantages and disadvantages has become commonplace for many students and teachers in modern world $[9,10]$. The problem for effective interaction in distance learning between teaching staff and students should be investigated more thoroughly in the nearest future.

\section{References}

1 T.E. Isaeva, The problem of functional stability of the competences of students in universities, Society: sociology, psychology, pedagogy, no.2, 2017, pp. 59-61

2 T.E. Isaeva, Pedagogical culture of a teacher as a condition and indicator of the quality of the educational process in higher education, Thesis. ... doct. ped. n. Rostov-on-Don, 2003,412 p

3 A.N. Kolesnichenko, Features of the use of multimedia technologies in teaching a foreign language at a university, Proceedings of the 17th International Scientific and Practical Conference "Teacher of Higher Education in the XXI Century": Rostov n / a: FGBOU VO RGUPS, 2020, pp.215-220

4 A.P. Kononenko, Modern methods for teaching a foreign language in educational institutions: Colloquium journal, no.9 (33), vol. 6, 2019,pp. 81-83

5 A.P. Kononenko, The cost of obtaining various diplomas of higher education in a number of leading countries of the world: Actual problems of the humanities and natural sciences, no.09 (80), 2015, pp. 127-130

$6 \mathrm{Yu}$. Yu. Kotlyarenko, E-learning or distance learning (empirical research on the example of a foreign language): Kazan Pedagogical Journal, no. 3 (140), 2020, pp. 75 83

7 I.V. Odaryuk, The use of lapbook technology in the organization of academic and professional interaction with students of a technical university in a foreign language: Samara Scientific Bulletin, vol. 9, no. 2 (31), 2020, pp. 266-269 
8 Modern digital and information and communication technologies for the formation of universal competencies of university students in the process of teaching foreign languages: collective monograph / T.E. Isaeva, O. N. Bessarabova and others: FSBEI VO RSTU. Rostov-on-Don, 2020, p. 232

9 E. Sh. Shefieva, Features of the use of information technologies of teaching for the subject Olympiad in English at the university: Bulletin of the Volgograd State Pedagogical University, no. 2 (135), 2019, pp. 75-79

10 E. Sh. Shefieva, The use of Internet services in distance learning, including foreign languages, in the context of the coronavirus pandemic, Proceedings of the 17th International Scientific and Practical Conference "Teacher of higher education in the XXI century": Rostov n / a: FGBOU VO RGUPS, 2020, 462 p. 